\title{
Inter-Alpha Inhibitor Protein Administration Improves Survival From Neonatal Sepsis in Mice
}

\author{
KULTAR SINGH, LING XIU ZHANG, KRESO BENDELJA, RYAN HEATH, SHAUN MURPHY, SURENDRA SHARMA, \\ JAMES F. PADBURY, AND YOW-PIN LIM
}

\begin{abstract}
Department of Pediatrics [K.S., S.S., J.F.P.], Women \& Infants' Hospital, Brown Medical School, Providence, Rhode Island 02905; Division of Hematology/Oncology [L.X.Z., K.B., R.H., S.M., Y.-P.L.], Rhode Island Hospital, Brown Medical School, Providence, Rhode Island 02903; ProThera Biologics [Y.-P.L.], East Providence, Rhode Island 02914
\end{abstract}

\begin{abstract}
Inter-alpha inhibitor proteins (IaIp) are serine proteases inhibitors that modulate endogenous protease activity and have been shown to improve survival in adult models of sepsis. We evaluated the effect of IaIp on survival and systemic responses to sepsis in neonatal mice. Sepsis was induced in 2-d-old mice with lipopolysaccharide (LPS), Escherichia coli, and group B Streptococci. Sepsis was associated with $75 \%$ mortality. IaIp, given by i.p. administration at doses between 15 and $45 \mathrm{mg} / \mathrm{kg}$ from 1 to $6 \mathrm{~h}$ after the onset of sepsis, improved survival to $\sim 90 \%$ ( $p=0.0159)$ in both LPS-induced sepsis and with live bacterial infections. The greatest effect was on reversal of hemorrhagic pneumonitis. The effects were dose and time dependent. Systemic cytokine profile and tissue histology were examined. Survival was compared in IL-10 knock out animals. Systemic cytokine levels including TNF- $\alpha$ and IL-10 were increased after induction of sepsis and modulated significantly after IaIp administration. Because the effect of IaIp was still demonstrable in IL-10 deficient mice, we conclude the beneficial effects of IaIp is because of suppression of proinflammatory cytokines such as TNF- $\alpha$ rather than augmentation of IL-10. IaIp may offer significant benefits as a therapeutic adjunct to treatment of sepsis in neonates and adults. (Pediatr Res 68: 242-247, 2010)
\end{abstract}

Cepsis is a leading cause of morbidity and mortality in $\checkmark$ newborn and preterm infants (1-3). In a large, multicenter, prospective, cross-sectional study from the NICHD Neonatal Research Network, the incidence of late onset nosocomial infection was $16 \%$ of 2,416 infants enrolled at 12 sites (3). The high continuing morbidity and mortality caused by sepsis, septic shock, and multiple organ failure may be attributable to the fact that the mediators and factors responsible for the pathophysiologic alterations of sepsis are not fully understood (4). Antibiotic therapy may not be sufficient to reverse systemic inflammation and consequent organ injury accompanying sepsis.

Mediators involved in the progression of sepsis can induce the activation of phagocytes that release neutrophil proteases (5). Experimental and clinical data have demonstrated that increased activity of neutrophil-derived serine proteases, such

Received January 14, 2010; accepted May 6, 2010.

Correspondence: James F. Padbury, M.D., Department of Pediatrics, Women \& Infants Hospital, 101 Dudley Street, Providence, RI 02905; e-mail: jpadbury@wihri.org Supported by Grants from the NIH NICHD R21 HD047600 and NCRR P20 RR018728.

Y-P.L. has equity in the company ProThera Biologics where the IaIp protein preparations used in these experiments were produced and where the Western blot assays were performed. as leukocyte elastase and cathepsin G, play a prominent role in sepsis-related tissue damage (6). Administration of protease inhibitors has been proposed as a therapeutic strategy to restore the balance between proteases and protease inhibitors in sepsis (7). One such inhibitor is the inter-alpha inhibitor protein (IaIp) family (8-10). This is a group of structurally related serine protease inhibitors found at relatively high concentrations in human plasma. IaIp proteins are composed of heavy and light polypeptide subunits that are covalently linked by a glycosaminoglycan chain (10-12). The light chain, also called bikunin, contains the serine protease inhibitory activity of the molecules (13). Bikunin is inactive when cross-linked in these complexes until it is released by partial proteolytic degradation. After cleavage from the complex, bikunin is cleared rapidly from plasma by glomerular filtration and receptor-mediated uptake (14).

IaIp proteins are involved in many physiologic and pathologic activities. This includes tumor invasion and metastasis (15), stabilization of the extracellular matrix (8), inflammation, and wound healing (16). Recently, the involvement of IaIp in inflammatory diseases has become an area of intensive investigation. The release of neutrophil proteases, especially human leukocyte elastase, has been implicated in the progression of complications in both adult and neonatal patients with sepsis $(9,17,18)$. Plasma IaIp is particularly sensitive to cleavage by neutrophil elastase. The light chain released from the IaIp complex then exerts its inhibitory activity on serine proteases (19). In vitro, IaIp inhibits several serine proteases that are involved in inflammation, including elastase, plasmin, and cathepsin G (20). Clinical studies of patients with severe sepsis have revealed significant reduction in circulating IaIp caused by consumption and accompanied by an extended secretion of elastase $(9,17,18)$.

We have demonstrated markedly decreased concentrations of IaIp in plasma of septic adults $(9,21,22)$ and neonates $(23,24)$. Furthermore, the degree of reduction of IaIp in adults correlates with increased mortality $(9,21,22)$. In experimental models of sepsis, we have demonstrated that improved survival, improved hemodynamic and physiologic stability, re-

\footnotetext{
Abbreviations: CFU, colony forming units; GBS, group B $\beta$ hemolytic Streptococcus; HSA, human serum albumin; IaIp, inter-alpha inhibitor proteins; LPS, lipopolysaccharide; IL-10 ${ }^{-/-}, 10$ deficient animals
} 
duced hepatic injury, and reduced inflammatory cytokine production after IaIp $(25,26)$. Jourdain et al. (27) have shown that administration of human IaIp markedly improved hemodynamics, tissue oxygenation, and pulmonary hypertension in a porcine model of endotoxic shock. There are no experimental studies on the effects of IaIp administration in neonates. The goal of our studies was to examine the effects of IaIp administration on survival and inflammatory cytokine production in microbiologically relevant models of neonatal sepsis $(28,29)$.

\section{MATERIALS AND METHODS}

IaIp preparation. Human IaIp was purified as previously described by a combination of cryoprecipitation, solid phase extraction, and a series of chromatographic separations involving ion-exchange, heparin affinity, and hydroxyl apatite columns $(25,26)$. The purity is $>95 \%$. This highly purified IaIp has shown no side effects including toxicity, thrombogenicity, or hypotension in studies in adult model systems $(25,26,30)$.

Neonatal Sepsis Models. All animal experiments were conducted under a protocol approved by the Institutional Animal Care and Use Committee, which conforms to the Guide for the Care and Use of Laboratory Animals published by the US National Institutes of Health (National Institutes of Health Publication No. 85-23, revised 1996) and in accordance with the Declaration of Helsinki principles. All mice used in this study were housed in a specific pathogen-free facility under the care of the Central Research Department of Rhode Island Hospital. All strains of mice, C57BL/6 IL-10 deficient animals (IL-10 ${ }^{-1-}$ ), C57BL/6 wild type, and BALB/C wild type, were obtained from the Jackson Laboratory (Bar Harbor, ME).

The dose-dependent effects of lipopolysaccharide (LPS) were compared by injection of 5, 10, or $25 \mu \mathrm{g}$ s.c. in 2-d-old, mixed-gender BALB/c wild-type mice. The LPS preparation used was serotype O26:B6 Escherichia coli LPS (Sigma Chemical Co. Chemical, St. Louis, MO). Injection of $25 \mu \mathrm{g}$ of LPS s.c. resulted in survival of $25 \%$ after $80 \mathrm{~h}$. This dose was used in subsequent experiments. Two-day-old mice $(n=22)$ were injected with LPS and randomized into two groups. The IaIp animals $(n=12)$ received $30 \mathrm{mg} / \mathrm{kg}$ body weight of highly purified human IaIp i.p. $1 \mathrm{~h}$ after LPS. Controls $(n=$ 10) received equal amount of human serum albumin (HSA). Survival was observed every $2 \mathrm{~h}$ for $80 \mathrm{~h}$. Results were compared with the two groups. The effect of delayed administration of IaIp was tested by administration of IaIp to $6 \mathrm{~h}$ after the LPS dose. The dependence of survival on the dose of IaIp was compared by administration of three different doses, $15 \mathrm{mg} / \mathrm{kg}(n=5), 30$ $\mathrm{mg} / \mathrm{kg}(n=10)$, and $45 \mathrm{mg} / \mathrm{kg}(n=6)$ body weight $3 \mathrm{~h}$ after LPS. This dosing range was based on the previous studies in adult animal models $(25,26)$.

Survival was also determined after injection of live E. coli or type 1 GBS. The virulent strain of K1 subtype of $E$. coli that we used was a clinical strain obtained from Dr. Stephen Opal Memorial Hospital of Rhode Island. The GBS strain was a clinical isolate obtained at Women \& Infants Hospital of Rhode Island. Bacteria from a fresh overnight culture was inoculated into Luria-Bertani broth and grown to log phase in a shaking culture flask at $37^{\circ} \mathrm{C}$ and monitored spectrophotometrically until achieving an $\mathrm{OD}_{560}$ of 0.38 . Previous experiments using serial dilutions and direct plating of that innocu- lum were used to generate a standard curve for colony forming units $(\mathrm{CFU}) / \mathrm{mL}$ of culture. Fresh culture was serially diluted into sterile PBS. The final injection volume for all doses of bacteria was $25 \mu \mathrm{L}$. Survival was examined after s.c. administration of $10^{4}$ to $10^{7}$ E. coli CFU/pup. The effects of exogenous IaIp were examined after the administration of $30 \mathrm{mg} / \mathrm{kg}$ IaIp or HSA i.p. $1 \mathrm{~h}$ after the E. coli. Similarly, the dose-dependent effects of GBS were determined by s.c. administration of $10^{4}$ to $10^{7} \mathrm{CFU} /$ pup, and the effects on survival were examined after a dose of $30 \mathrm{mg} / \mathrm{kg}$ IaIp $1 \mathrm{~h}$ after the GBS. All experiments with animals were approved by the Institutional Animal Care and Use Committee. The effect of IaIp was also compared in wild-type animals and in animals in which the anti-inflammatory cytokine IL-10 had been disrupted (IL-10 $0^{-\prime-}$ ). Because of their heightened mortality in response to LPS, the dose response for lethality was first established in IL-10 $10^{-/-}$ neonatal mice. The effect of IaIp on survival was then examined after LPS injection, as in the experiments with wild type animals, by i.p. injection of 30 $\mathrm{mg} / \mathrm{kg}$ IaIp or human albumin $1 \mathrm{~h}$ after s.c. LPS.

Inflammatory Cytokine Responses. To examine the effects of IaIp on inflammatory responses, plasma cytokine levels were measured in IaIp- and albumin-treated groups. LPS administered s.c. as above was followed $1 \mathrm{~h}$ later by $30 \mathrm{mg} / \mathrm{kg}$ body weight of i.p. IaIp or albumin. Animals were killed at intervals, and pooled trunk blood was collected from three pups at 2, 6, 12, 24, 48 , and $72 \mathrm{~h}$ after the LPS injection, from both IaIp and albumin-treated groups. Plasma was separated immediately by centrifugation and stored at $-70^{\circ} \mathrm{C}$ for measurement of MCP-1, TNF-a, IL-10, IL-12p70, IFN- $\gamma$, and IL- 6 by RIA (9).

Statistics. The log rank test was used to calculate statistical differences in survival between the IaIp and the control group. Unpaired t testing was used to compare whether the group means were appropriate. In both cases, $p<$ 0.05 was considered as statistically significant.

\section{RESULTS}

We administered graded doses of LPS s.c. to 2 to 3-d-old BALB/c wild type mice (Fig. 1 panel $A$ ). As can be seen, there was a dose-dependent mortality that reached $60-70 \%$ by $48 \mathrm{~h}$ after the administration of $25 \mu \mathrm{g}$ per pup dose. In Figure $1 B$, it can be seen that administration of $30 \mathrm{mg} / \mathrm{kg}$ i.p. of IaIp $1 \mathrm{~h}$ after LPS challenge reversed mortality from 60 to $70 \%$ by $40 \mathrm{~h}$ to prolonged survival in $\sim 90 \%$ of the pups. Increasing the dose to $45 \mathrm{mg} / \mathrm{kg}$ had no additional salutary effect. However, reducing the dose to $15 \mathrm{mg} / \mathrm{kg}$ decreased survival to $60 \%$, which was still statistically significant, $p<0.05$. We examined the timing of IaIp administration. Administration of IaIp as long as to $3 \mathrm{~h}$ after the LPS was still highly protective. If IaIp was administered, 1 to $3 \mathrm{~h}$ after LPS survival remained between 80 and 90\%, Figure 1C. Delaying administration for $6 \mathrm{~h}$ reduced survival, which was nonetheless still significantly better than vehicle alone.
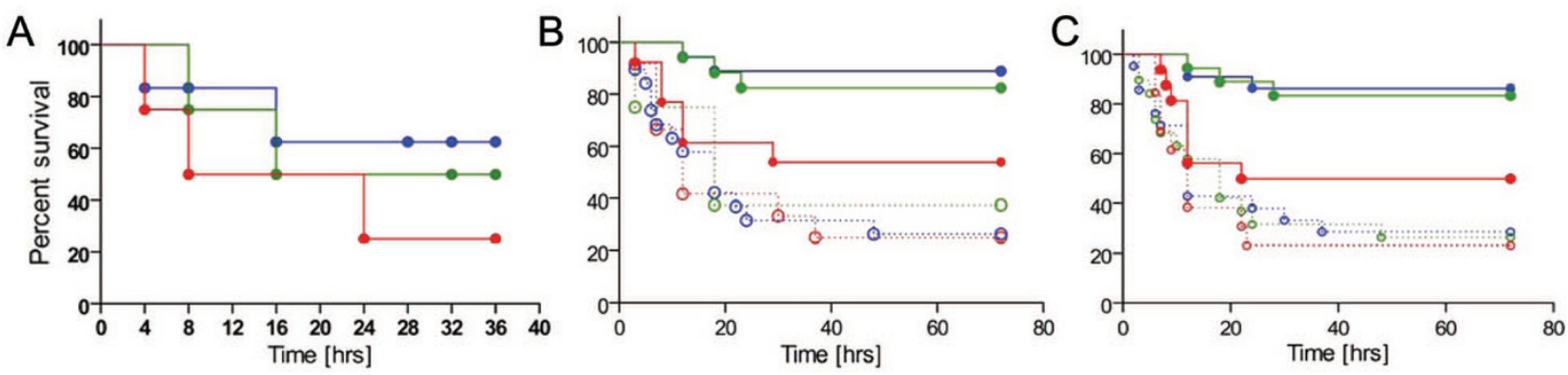

Figure 1. The effect of IaIp on mortality in 2-d-old mice. A, Survival following 5 (blue, $n=5$ ), 10 ( green, $n=4$ ), or 25 (red, $n=4$ ) $\mu \mathrm{g}$ of LPS per pup. $B$, Dose-dependent effects of 15 (red, $n=13), 30$ (blue, $n=18$ ), or 45 (green, $n=17$ ) mg/kg IaIp i.p. $1 \mathrm{~h}$ later after LPS compared with HSA controls at the same concentrations: 15 (red dotted, $n=12$ ), 30 (blue dotted, $n=19$ ), and 45 (green dotted, $n=9$ ) mg/kg. Both 30 and $45 \mathrm{mg} / \mathrm{kg}$ were significantly different from the $15 \mathrm{mg} / \mathrm{kg}$ group, $p<0.004$. C, Effect of delayed administration. Animals received $30 \mathrm{mg} / \mathrm{kg}$ IaIp at 1 (blue, $n=23$ ), 3 (green, $n=18$ ), or $6 \mathrm{~h}$ (red, $n=16$ ) after LPS. IaIp resulted in significantly better survival than each respective control, $p<0.001$. HSA controls at the same time points: 1 (blue dotted, $n=19), 3$ (green dotted, $n=19$ ), and $6 \mathrm{~h}$ (red dotted, $n=13$ ). 

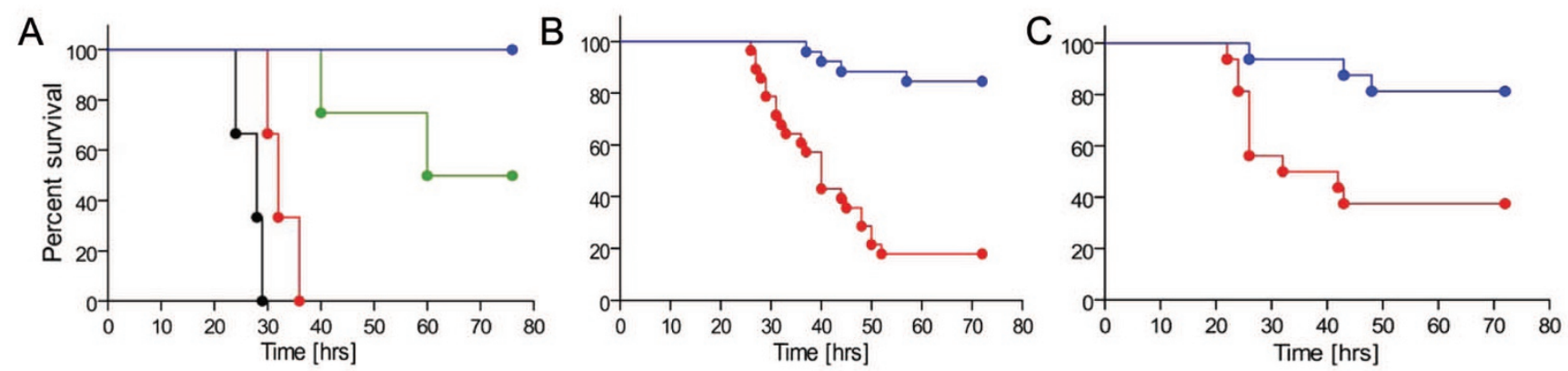

Figure 2. The effect of IaIp administration on survival after s.c. administration of live bacteria in 2-d-old BALB/c mice. A, Survival after s.c. injection of $10^{4}$ (blue), $10^{5}$ (green), $10^{6}$ (red), and $10^{7}$ (black) CFU E. coli per pup. B, Dose-dependent effect of IaIp on survival after E. coli administration. Control animals ( $r e d, n=28)$ received i.p. HSA, and IaIp-treated animals (blue, $n=26$ ) received $30 \mathrm{mg} / \mathrm{kg}$ IaIp i.p. $1 \mathrm{~h}$ later. IaIp-treated animals had significantly better survival than either control group, $p<0.05$. C, The effect of IaIp administration on survival after s.c. administration of group B Streptococci. IaIp-treated animals (blue, $n=17$ ) received $30 \mathrm{mg} / \mathrm{kg}$ IaIp i.p. $1 \mathrm{~h}$ later. IaIp-treated animals had significantly better survival than the HSA control group (red, $n=16$ ).

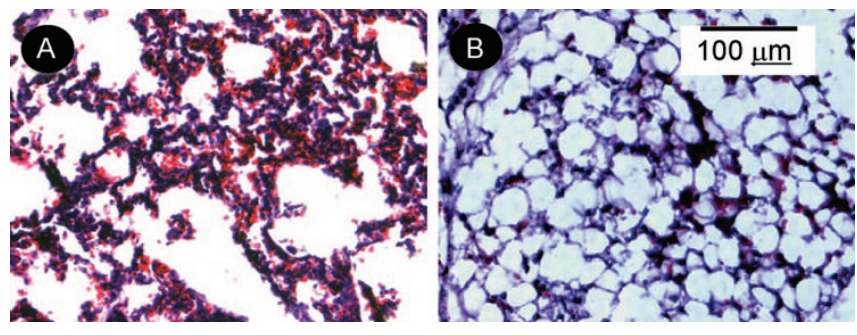

Figure 3. The effect of IaIp on lung histology after LPS. Animals were given LPS followed by HSA $(A)$ or $30 \mathrm{mg} / \mathrm{kg}$ IaIp $(B)$. Hematoxylin and eosin stain. Magnification $\times 40$.

We examined the effects of IaIp on E. coli and group B $\beta$ hemolytic Streptococcus (GBS) sepsis, the two most relevant pathogens in neonatal sepsis in human infants, to assess veracity of protection $(2,3,28,29,31)$. The virulent subtype of E. coli was grown to logarithmic phase in culture and then administered s.c. at doses from $4 \times 10^{5}$ up to $2 \times 10^{7}$ CFU/animal, Figure $2 A$. There was a high degree of lethality associated with the two highest doses, whereas $4 \times 10^{5} \mathrm{CFU}$ per pup resulted in reproducible lethality between 60 and $80 \%$ (Fig. $2 A$ and $B$ ). Administration of $30 \mathrm{mg} / \mathrm{kg}$ of IaIp $1 \mathrm{~h}$ following the E. coli improved survival to $\sim 90 \%$, Figure $2 B$. Similar lethality and response to administration of IAIP was seen with a clinical isolate of type I GBS, Figure $2 C$. The s.c. administration of GBS resulted in $60 \%$ overall mortality in the albumin-treated group. Survival was increased to $80 \%$ after the administration of IaIp in the animals injected with GBS.

To examine the mechanisms of protection of IaIp, tissue samples were taken from randomly selected pups $24 \mathrm{~h}$ after the administration of $25 \mu \mathrm{g}$ of LPS. Histologic sections were reviewed by a pathologist not aware of the treatment groups. Sections of the lung parenchyma after LPS from an animal that received IaIp and sections after LPS in a control animal that received albumin are shown in Figure 3. The control lung showed marked thickening of the alveolar septae, a pronounced polymorphonuclear leukocyte infiltration, and some pulmonary hemorrhage, Figure $3 A$. In contrast, IaIp administration was associated with preservation of largely normal lung parenchymal architecture, Figure $3 B$. Changes in other organs (liver, kidney, and intestine) were similar but less pronounced (not shown). Whole blood and plasma were col-

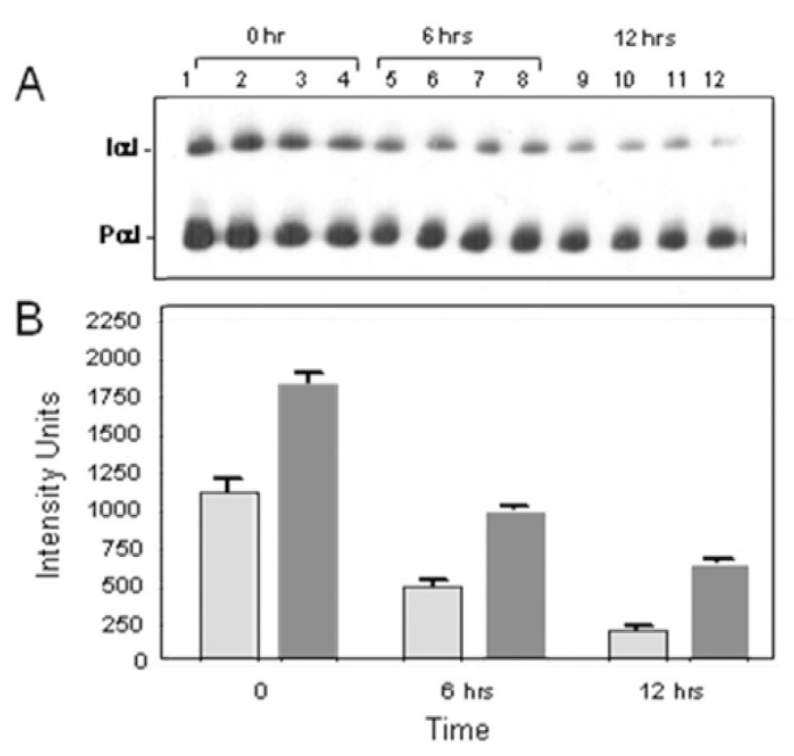

Figure 4. Western blot $(A)$ showing changes in endogenous, mouse IaIp (gray), and the Prealpha Inhibitor (dark gray) after the administration of LPS. $B$, The differences between each time point are all significant, $p<0.05$.

lected and examined by Western blot and ELISA to determine the time course for decrements in endogenous, mouse IaIp, and the prealpha inhibitor. The plasma concentration of both IaIp and PaI decreased significantly after the LPS-induced sepsis, Figure $4 A$. The differences between each time point are all significant, Figure $4 B, p<0.05$.

To examine the effect of IaIp on systemic immune responses, LPS was administered to animals as described above followed by timed sacrifice and collection of trunk blood for cytokine measurements. The results are shown in Figure 5. By $3 \mathrm{~h}$ after LPS, the plasma concentration of the proinflammatory cytokine TNF- $\alpha$ was increased to $\sim 25,000 \mathrm{pg} / \mathrm{mL}$ and remained elevated for $12 \mathrm{~h}$. Similarly, the immunomodulatory cytokine IL-10 was increased after LPS injection, reaching a peak concentration of $>2,500 \mathrm{pg} / \mathrm{mL}$ at $6 \mathrm{~h}$. Most remarkably, administration of IaIp $(30 \mathrm{mg} / \mathrm{kg}) 1 \mathrm{~h}$ after LPS injection nearly completely attenuated the increase in the plasma concentration of TNF- $\alpha$. TNF- $\alpha$ was reduced to almost baseline levels at $3 \mathrm{~h}$ after IaIp $(p<0.03)$. In contrast, the increase in 

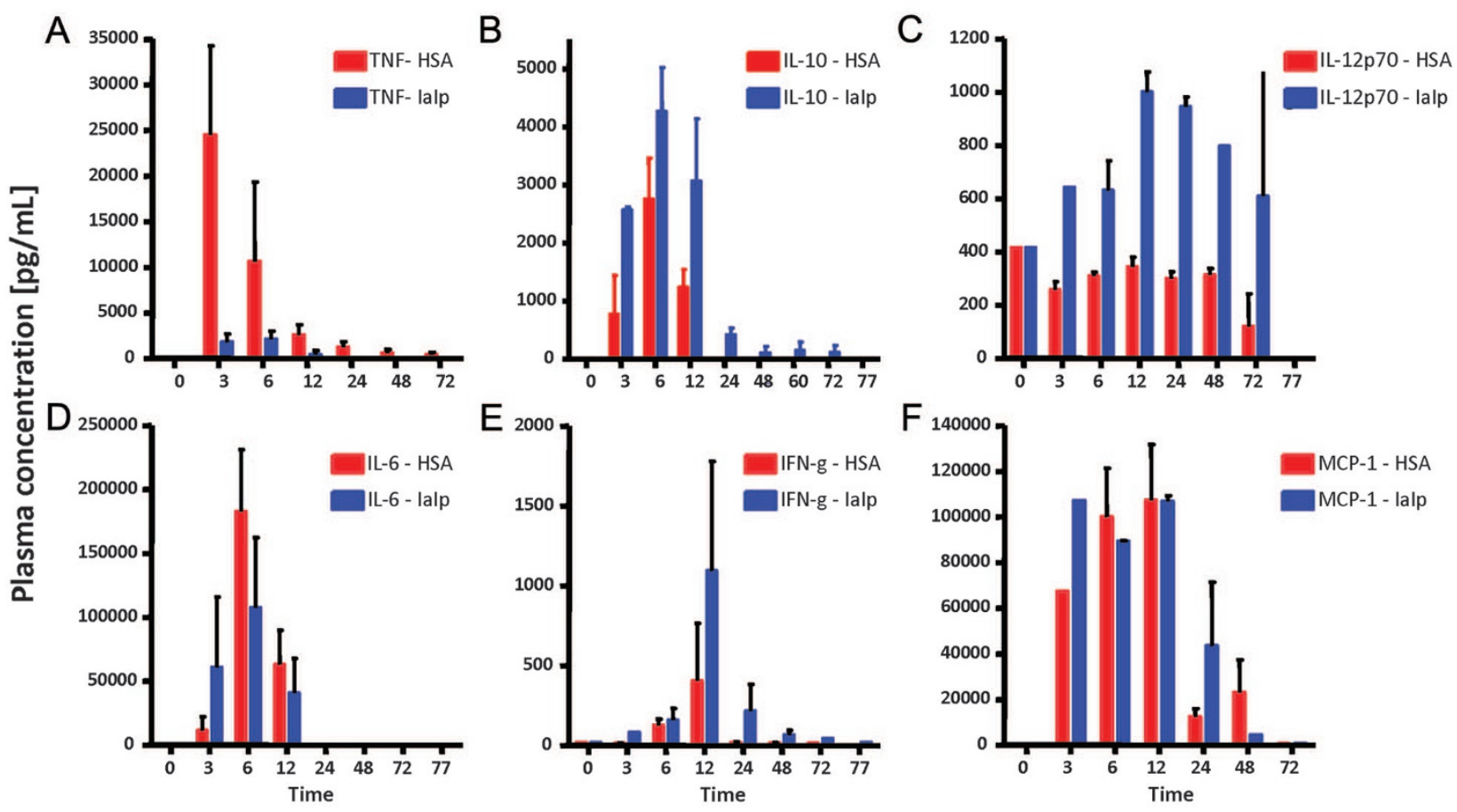

Figure 5. The effect of LPS on systemic cytokine levels. Animals received LPS, HSA, and IaIp as described in the Methods section. Cytokines were measured by RIA $3,6,12,24,48$, and 72 h later. Results were compared by two-way ANOVA. $A$, TNF- $\alpha, p=0.0313 ; B$, IL-10, $p=0.0377 ; C$, IL-12p70, $p=0.0024$; $D$, IL-6, $p=0.649 ; E$, IFN- $\gamma, p=0.141 ; F$, MCP- $1, p=0.4948$.

IL-10 was augmented and prolonged by IaIp $(p<0.04)$. Similarly, IaIp augmented the increase in plasma IL-12p70 $(p<0.002)$. The increase in IL-6 at $6 \mathrm{~h}$, followed the maximum increase in TNF- $\alpha$ and was modestly attenuated by IaIp administration. There was much less of an effect of IaIp on the changes in MCP-1 after LPS.

To determine the contributions to the beneficial effect of IaIp on survival from suppression of proinflammatory cytokine production or augmentation of IL-10 secretion, we performed similar experiments in animals in which the $I L-10$ gene had been disrupted (IL-10 $0^{-1-}$ ). The IL- $10^{-1-}$ animals showed a markedly heightened susceptibility to mortality after LPS. We systematically compared $10,2.5$, and $0.25 \mu \mathrm{g}$ in IL- $10^{-1-}$ animals (Fig. 5B). LPS was highly lethal but by reducing the dose to $0.25 \mu \mathrm{g} / \mathrm{mouse}$, we observed a survival of up to $40 \%$ at $60 \mathrm{~h}$. Administration of IaIp to IL-10 ${ }^{-1-}$ animals $1 \mathrm{~h}$ following $0.25 \mu \mathrm{g}$ LPS was associated with $>90 \%$ survival (Fig. 6B). IaIp prolonged survival in the IL-10 ${ }^{-/-}$ animals receiving the higher LPS doses, albeit death was observed in all by $50 \mathrm{~h}(p<0.05)$.

\section{DISCUSSION}

In these studies, we show improved survival after the administration of IaIp in neonatal sepsis because of LPS and live E. coli and GBS, the most important organisms in the epidemiology of neonatal sepsis $(3,20,31)$. Taken together with our other findings, these results suggest that administration of IaIp elicits potent immunomodulatory actions that lead to survival in neonatal sepsis even when administered at delayed time points. These observations suggest that defi-

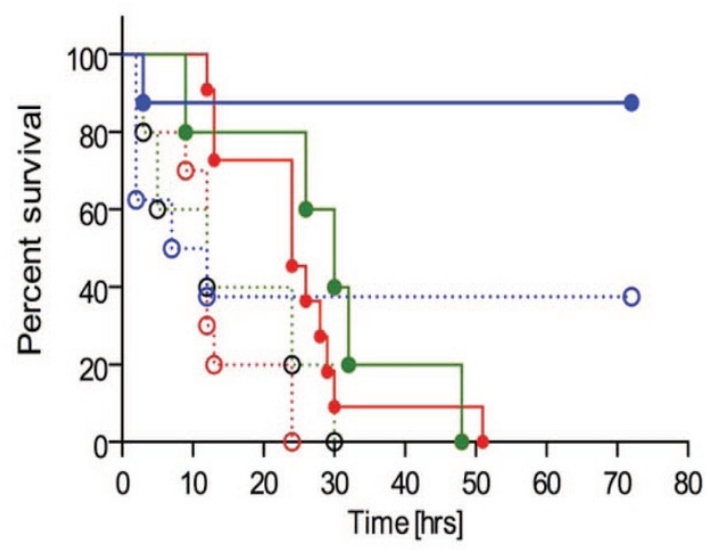

Figure 6. Survival after LPS administration in IL-10 $10^{-1-}$ mice. Animals were treated with LPS, $0.25,2.5$, or $10 \mu \mathrm{g}$ per animal, as described in the Methods section. Animals were treated with IaIp [IaIp + LPS 0.25 (blue, $n=8$ ); IaIp + LPS 2.5 (green, $n=5)$; and IaIp + LPS $10($ red, $n=10)$ ] or HSA [HSA + LPS 0.25 (blue dotted, $n=8$ ); HSA + LPS 2.5 (green dotted, $n=5$ ); and HSA + LPS 10 (red dotted, $n=10$ )] as described in methods $1 \mathrm{~h}$ after LPS. Animals were examined every $4 \mathrm{~h}$ for survival. All IaIp-treated animals had significantly better survival than each of their respective control groups, $p=$ 0.006 .

ciency of these regulatory protease inhibitors may play a pathophysiologic role in systemic inflammation and sepsis $(32,33)$.

The host immune response leads to a proinflammatory cascade, which continues even after the responsible organisms are killed despite administration of antibiotics. Recently, studies in adult humans with severe sepsis and organ dysfunction have demonstrated an improvement in survival after adminis- 
tration of antibiotics and recombinant-activated protein $\mathrm{C}$ (34). The reduction in the risk of death was modest $(6 \%)$; however, there was an apparent increase in associated risk of bleeding. Activated protein $\mathrm{C}$ promotes fibrinolysis and suppresses immune system activation. The increase in bleeding with activated protein $\mathrm{C}$ administration is a relatively strong contraindication in newborn infants, especially in preterm infants. Indeed, a randomized, controlled trial in children aged 38-wk gestation to $17 \mathrm{y}$ failed to identify any benefits of activated protein $\mathrm{C}$ but noted an increase in the risk of bleeding in infants $<60 \mathrm{~d}$ of age (35).

Clinical studies in patients with severe sepsis show significant reduction in the circulating concentration of IaIp that correlate with increased mortality in septic adult patients (9,21-24). We and others have shown improvement in survival of adult animals in experimental models of sepsis associated with a decrease in organ dysfunction and a marked reduction in the production/secretion of the proinflammatory cytokine TNF- $\alpha$ (25-27). The experiments reported here demonstrate that i.p. administration of IaIp to 2-d-old mice after the induction of sepsis syndrome was associated with a doseand time-dependent improvement in survival, suppression of secretion of proinflammatory cytokines such as TNF- $\alpha$, and augmentation of IL-10 and IL-12p70 production. The improvement in survival was seen in animals with genetic deficiency in IL-10, suggesting that the beneficial effect of IaIp on survival resulted from alteration in TNF- $\alpha$ levels and other cytokines rather than augmentation of IL-10 or IL-12p70 secretion.

Neutrophils, monocytes, macrophages, and Kupfer cells all produce significant amounts of TNF- $\alpha$ when exposed to high levels of endotoxin. Coeshut et al. (36) have further shown that neutrophils contribute to augmented TNF- $\alpha$ and IL- $1 \beta$ secretion by release of proteases, such as proteas-3, elastase, and cathepsin G, in a TNF- $\alpha$ converting enzyme (TACE) and ICE (IL-1 $\beta$ converting enzyme) independent manner. Similarly, IL-6 is produced in response to stimulation by endotoxin IL-1 $\beta$ and TNF- $\alpha$ (37). We observed marked suppression in the levels of TNF- $\alpha$ in the animals treated with IaIp. Taken together, these findings stress different pathways of TNF- $\alpha$ biosynthesis/processing and provide insight into mechanisms for the immunomodulatory effect of the protease inhibitor IaIp. Hepatic Kupfer cells are the main source of IL-10, an immunomodulatory cytokine that protects mice against endotoxic shock by preventing excessive production of proinflammatory cytokines (38). Because the effect of IaIp on survival was still demonstrable in IL-10 deficient mice, we conclude the beneficial effects of IaIp is because of more suppression of proinflammatory cytokines such as TNF- $\alpha$ and others rather than augmentation of IL-10 production.

Models of sepsis in experimental animals have been used widely to develop new and effective therapies. Models that use live organisms better recapitulate the characteristics of disease progression and organ dysfunction that accompanies sepsis than models using endotoxin alone $(8,29)$. IaIp has been demonstrated to be effective now in a wide range of conditions $(25,26,30)$. IaIp is not only therapeutic but also may have both diagnostic and prognostic value. As already noted, low levels of IaIp are associated with sepsis in adult humans and human neonates (9,21-24). Most recently, we have demonstrated that in longitudinal studies of IaIp levels in severely septic patients that failure of IaIp levels to recover over the first $5 \mathrm{~d}$ of sepsis is associated with a poor outcome (22). In addition, our most recent data looked cross-sectionally at large numbers of human newborns with sepsis and GA and postnatally agematched controls. We studied the receiver/operating characteristics needed to identify optimal predictive values of plasma IaIp levels in neonatal sepsis (24). Using a computer-derived cutoff value of $177 \mu \mathrm{g} / \mathrm{mL}$, we demonstrated a sensitivity of $89.5 \%$, a specificity of $99 \%$, a positive predictive value of $95 \%$, and a negative predictive value of $98 \%$. The area under the ROC curve was $0.94, p<0.001$.

In this study, we observed comparable survival after the induction of a systemic immune response syndrome (SIRS) mimicking sepsis because of LPS in animals that received either 30 or $45 \mathrm{mg} / \mathrm{kg}$ body weight IaIp, which suggests that larger doses are unlikely to offer additional benefits. We also compared administration of IaIp after $1 \mathrm{~h}$ with delayed administration of IaIp until 3 or $6 \mathrm{~h}$. The beneficial effects on survival were seen even when IaIp administration was delayed 3 to $6 \mathrm{~h}$ after induction of sepsis. The results further demonstrate the effects of IaIp administration on immune system activation and organ dysfunction. Our results suggest that administration of IaIp exerts potent immunomodulatory actions that lead to a beneficial effect in septic newborn mice. IaIp may be an effective adjunct to treatment of severe sepsis in neonates or adults and warrants clinical investigation.

Acknowledgments. We thank Michael P. Sherman, MD, Professor, Southern Illinois University School of Medicine, and Rashmin C. Savani, Professor and Chief, Division of Neonatology, University of Texas Southwestern Medical Center, for their intellectual contributions.

\section{REFERENCES}

1. Hyde TB, Hilger TM, Reingold A, Farley MM, O'Brien KL, Schuchat A; Active Bacterial Core surveillance (ABCs) of the Emerging Infections Program Network 2002 Trends in incidence and antimicrobial resistance of early-onset sepsis: population-based surveillance in San Francisco and Atlanta. Pediatrics 110:690-695

2. Puopolo KM, Madoff LC, Eichenwald EC 2005 Early-onset group B streptococcal disease in the era of maternal screening. Pediatrics 115:1240-1246

3. Stoll BJ, Hansen NI, Higgins RD, Fanaroff AA, Duara S, Goldberg R, Laptook AR, Walsh M, Oh W, Hale E 2005 Very low birth weight preterm infants with early onset neonatal sepsis: the predominance of gram-negative infections continues in the National Institute of Child Health and Human Development Neonatal Research Network, 2002-2003. Pediatr Infect Dis J 24:635-639

4. Cohen J 2002 The immunopathogenesis of sepsis. Nature 420:885-891

5. Jochum M, Gippner-Steppert C, Machleidt W, Fritz H 1994 The role of phagocyte proteases and proteinase inhibitors in multiple organ failure. Am J Respir Crit Care Med 150:S123-S130

6. Burg ND, Pillinger MH 2001 The neutrophil: function and regulation in innate and humoral immunity. Clin Immunol 99:7-17

7. Siebeck M, Fink E, Weipert J, Jochum M, Fritz H, Spannagl M, Kroworsch P, Shimamoto K, Schweiberer L 1993 Inhibition of plasma kallikrein with aprotinin in porcine endotoxin shock. J Trauma 34:193-198

8. Bost F, Diarra-Mehrpour M, Martin JP 1998 Inter-alpha-trypsin inhibitor proteoglycan family - a group of proteins binding and stabilizing the extracellular matrix. Eur J Biochem 252:339-346

9. Lim Y-P, Bendelja K, Opal SM, Siryaporn E, Hixson DC, Palardy JE 2003 Correlation between mortality and the levels of inter-alphainhibitors in the plasma of patients with severe sepsis. J Infect Dis 188:919-926

10. Zhuo L, Hascall VC, Kimata K 2004 Inter-alpha-trypsin inhibitor, a covalent protein-glycosaminoglycan-protein complex. J Biol Chem 279:38079-38082

11. Blom AM, Morgelin M, Oyen M, Jarvet J, Fries E 1999 Structural characterization of inter-alpha-inhibitor. Evidence for an extended shape. J Biol Chem 274:298-304 
12. Fries E, Blom AM 2000 Bikunin-not just a plasma proteinase inhibitor. Int J Biochem Cell Biol 32:125-137

13. Wachter E, Hochstrasser K 1981 Kunitz-type proteinase inhibitors derived by limited proteolysis of the inter-alpha-trypsin inhibitor: IV. The amino acid sequence of the human urinary trypsin inhibitor isolated by affinity chromatography. Hoppe Seylers Z Physiol Chem 362:1351-1355

14. Sjoberg EM, Blom A, Larsson BS, Alston-Smith J, Sjöquist M, Fries E 1995 Plasma clearance of rat bikunin: evidence for receptormediated uptake. Biochem J 308:881887

15. Kobayashi H, Suzuki M, Hirashima Y, Terao T 2003 The protease inhibitor bikunin, a novel anti-metastatic agent. Biol Chem 384:749-754

16. Fries E, Kaczmarczyk A 2003 Inter-alpha-inhibitor, hyaluronan and inflammation. Acta Biochim Pol 50:735-742

17. Kingsmore SF, Kennedy N, Halliday HL, Van Velkinburgh JC, Zhong S, Gabriel V, Grant J, Beavis WD, Tchernev VT, Perlee L, Lejnine S, Grimwade B, Sorette M, Edgar JD 2008 Identification of diagnostic biomarkers for infection in premature neonates. Mol Cell Proteomics 7:1863-1875

18. Mizon C, Piva F, Queyrel V, Balduyck M, Hachulla E, Mizon J 2002 Urinary bikunin determination provides insight into proteinase/proteinase inhibitor imbalance in patients with inflammatory diseases. Clin Chem Lab Med 40:579-586

19. Hirose J, Ozawa T, Miura T, Isaji M, Nagao Y, Yamashiro K, Nii A, Kato K, Uemura A 1998 Human neutrophil elastase degrades inter-alpha-trypsin inhibitor to liberate urinary trypsin inhibitor related proteins. Biol Pharm Bull 21:651-656

20. Potempa J, Kwon K, Chawla R, Travis J 1989 Inter-alpha-trypsin inhibitor. Inhibition spectrum of native and derived forms. J Biol Chem 64:15109-15114

21. Rucevic M, Fast LD, Jay GD, Trespalcios FM, Sucov A, Siryaporn E, Lim YP 2007 Altered levels and molecular forms of granzyme $\mathrm{k}$ in plasma from septic patients. Shock 27:488-493

22. Opal SM, Lim Y-P, Siryaporn E, Moldawer LL, Pribble JP, Palardy JE, Souza S 2007 Longitudinal studies of inter-alpha inhibitor proteins in severely septic patients: a potential clinical marker and mediator of severe sepsis. Crit Care Med 35:387-392

23. Baek YW, Brokat S, Padbury JF, Pinar H, Hixson DC, Lim Y-P 2003 Inter-alpha inhibitor proteins in infants and decreased levels in neonatal sepsis. J Pediatr 143:11-15

24. Chaaban H, Singh K, Lam J, Siryaporn E, Lim Y-P, Padbury JF 2009 The Role of Inter-alpha Inhibitor Protein in the Diagnosis of Neonatal Sepsis. J Pediatr 154:620622

25. Wu R, Cui X, Lim Y-P, Bendelja K, Zhou M, Simms HH, Wang P 2004 Delayed administration of human inter-alpha inhibitor proteins reduces mortality in sepsis. Crit Care Med 32:1747-1752

26. Yang S, Lim YP, Zhou M, Salvemini P, Schwinn H, Josic D, Koo DJ, Chaudry IH, Wang P 2002 Administration of human inter-alpha-inhibitors maintains hemodynamic stability and improves survival during sepsis. Crit Care Med 30:617-622
27. Jourdain M, Carrette O, Tournoys A, Fourrier F, Mizon C, Mangalaboyi J, Goudemand J, Mizon J, Chopin C 1997 Effects of inter-alpha-inhibitor in experimental endotoxic shock and disseminated intravascular coagulation. Am J Respir Crit Care Med 156:1825-1833

28. Buras JA, Holzmann B, Sitkovsky M 2005 Animal models of sepsis: setting the stage. Nat Rev Drug Discov 4:854-865

29. Esmon CT 2004 Why do animal models (sometimes) fail to mimic human sepsis? Crit Care Med 32:S219-S222

30. Opal SM, Artenstein AW, Cristofaro PA, Jhung JW, Palardy JE, Parejo NA, Lim Y-P 2005 Inter-alpha-inhibitor proteins are endogenous furin inhibitors and provide protection against experimental anthrax intoxication. Infect Immun 73:5101-5105

31. Baker CJ 1997 Group B streptococcal infections. Clin Perinatol 24:59-70

32. Garantziotis S, Hollingsworth JW, Ghanayem RB, Timberlake S, Zhuo L, Kimata K, Schwartz DA 2007 Inter-alpha-trypsin inhibitor attenuates complement activation and complement-induced lung injury. J Immunol 179:4187-4192

33. Wakahara K, Kobayashi H, Yagyu T, Matsuzaki H, Kondo T, Kurita N, Sekino H, Inagaki K, Suzuki M, Kanayama N, Terao T 2005 Bikunin suppresses lipopolysaccharide-induced lethality through down-regulation of tumor necrosis factor- alpha and interleukin-1 beta in macrophages. J Infect Dis 191:930-938

34. Bernard GR, Vincent JL, Laterre PF, LaRosa SP, Dhainaut JF, Lopez-Rodriguez A Steingrub JS, Garber GE, Helterbrand JD, Ely EW, Fisher CJ Jr; Recombinan human protein C Worldwide Evaluation in Severe Sepsis (PROWESS) study group 2001 Efficiency and safety of recombinant human activated protein $\mathrm{C}$ for severe sepsis. N Engl J Med 344:699-709

35. Nadel S, Goldstein B, Williams MD, Dalton H, Peters M, Macias WL, Abd-Allah SA, Levy H, Angle R, Wang D, Sundin DP, Giroir B; Researching severe Sepsis and Organ dysfunction in children: a global perspective (RESOLVE) study group.2007 Drotrecogin alfa (activated) in children with severe sepsis: a multicentre phase III randomised controlled trial. Lancet 369:836-843

36. Coeshott C, Ohnemus C, Pilyavskaya A, Ross S, Wieczorek M, Kroona H, Leimer $\mathrm{AH}$, Cheronis J 1999 Converting enzyme-independent release of tumor necrosis factor alpha and IL-1beta from a stimulated human monocytic cell line in the presence of activated neutrophils or purified proteinase 3. Proc Natl Acad Sci U S A 96:6261-6266

37. Robache-Gallea S, Morand V, Bruneau JM, Schoot B, Tagat E, Realo E, Chouaib S, Roman-Roman S 1995 In vitro processing of human tumor necrosis factor-alpha. J Biol Chem 270:23688-23692

38. van der Poll T, Marchant A, Buurman WA, Berman L, Keogh CV, Lazarus DD, Nguyen L, Goldman M, Moldawer LL, Lowry SF 1995 Endogenous IL-10 protects mice from death during septic peritonitis. J Immunol 155:5397-5401 